\title{
Bidding to manage North Sea data raises questions about privatisation
}

London. One important question raised by the British government's strategy for science is to what extent the private sector can be given responsibility for managing data on the country's natural resources - a task traditionally carried out by scientists at public institutions. This issue has surfaced after the Department of Trade and Industry (DTI), following new government guidelines, announced that it will shortly seek bids from private companies to manage geological data obtained from oil and gas exploration in the North Sea over the past 25 years.

The DTI says its approach will save money, but critics are concerned that it will undermine efforts to build up a national geological dataset and give the successful bidder an unfair commercial advantage. Companies engaged in North Sea exploration are now required to deposit geological data with what used to be the Department of Energy, which has been absorbed into DTI. In turn, the department has contracted out the management of this data through the Natural Environment Research Council to the British Geological Survey (BGS). Under a 1981 agreement, BGS's Hydrocarbons Unit in Edinburgh looks after both geological data and core samples from exploratory drilling submitted to the DTI - the latter in a storage facility built by the department and provides the government with advice on the energy potential of its offshore areas.

BGS has been told that its contract to provide these services, worth about $£ 2$ million a year, will not be automatically renewed at the end of March. Instead, DTI officials will in the next few weeks put out contracts for both jobs, based on the principle that the cost of public services should be tested against those available on the open market.

DTI's decision is not thought to reflect criticism of BGS, and a department spokesman said last week that a bid from the BGS would be welcome. The department has already held preliminary discussions with several companies, and the new contracts are expected to be announced by the end of March.

Nevertheless, the decision has led BGS scientists to wonder whether a tendering process based primarily on cost could overlook some of the less tangible advantages of the current arrangement, in particular access to the survey's unique expertise. "I think it is outrageous that there should be a major [geological] data set over which the BGS may not have control", says Mike Dean, head of the hydrocarbons unit in Edinburgh.

Various industrial organizations namely the UK Offshore Operators Asso- ciation, UK Onshore Operators Group and the British Independent Explorers Group are concerned that a successful bidder may face a possible conflict of interest if it also carries out consultancy work for individual companies. But the companies most likely to put in bids for the management contracts feel that such concern is exaggerated.

"If the BGS is providing a service to the DTI, why should other people not have the opportunity to provide the same service more efficiently?" says Simon Kendall of Simon Petroleum Technology in North Wales. "It is not against the national interest for the government to look for better value for money." Kendall says that it is "insulting" to suggest that the data would be less secure in private hands and points to his company's experience in handling confidential geological data for other countries.

Government officials are believed to feel

\section{Cuenod will head Human Frontier programme}

Tokyo. A Swiss neuroscientist will take charge of the Strasbourg secretariat of the Japanese-inspired international Human Frontier Science Program (HFSP), which supports research on the brain and biological functions.

The Strasbourg organization is expected to announce shortly that Michel Cuenod,

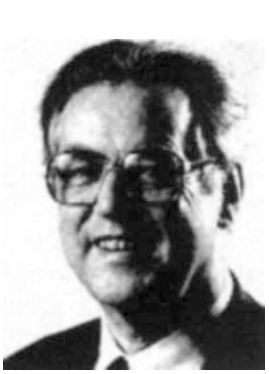

Michel Cuenod director of the Brain Research Institute at the University of $\mathrm{Zu}$ rich, has been chosen as secretary general. The appointment, welcomed in Japan, should reduce differences between Japanese founders of the programme and senior management in Strasbourg.

Relations between Japan, which provides most of the $\$ 40$ million a year spent by the programme, and the present secretary general, Sir James Gowans of Britain, have been strained since shortly after he took up his appointment in 1989. According to Japanese government officials and scientists, Gowans is out of tune with the basic philosophy of the programme; last year, Gowans decided to step down (see Nature 358, 527; 1992).

Cuenod was one of four candidates nominated by the nine members of the programme (Japan, the United States, Canada, France, that the concerns of critics are misguided, since they acknowledge that the integrity of the North Sea databank is vital to the longterm prosperity of Britain's offshore oil industry. In contrast, the BGS claims that the oil-exploration industry supports its contention that the current arrangements should continue. In a recent submission to the government on the organization of science, it says that its good relationships with the oil industry could be jeopardized by the DTI's new policies on market testing.

"We do market testing like anyone else, but I am concerned about whether this is an appropriate application", says BGS director Peter Cook. "We have been curating data for 150 years. What we have here is a government department primarily concerned with policy, and any policy-oriented department is going to take a short-term view.'

David Dickson

the United Kingdom, Italy, Germany, Switzerland and the European Communities). The others were Sydney Brenner of the University of Cambridge School of Medicine, Horst Sund of the University of Konstanz, Germany, and Lawrence Bogorad of Harvard University (see Nature 359, 567; 1992).

The field was reduced to Cuenod and Sund at a meeting in November of the HFSP council of scientists in Strasbourg. Later that month, at a meeting of the board of trustees with representatives of all members, Cuenod emerged as the favoured candidate. This Monday, Cuenod confirmed that he will accept an offer to take the job.

Cuenod now represents Switzerland in the HFSP science council and is popular with Japanese officials and scientists associated with the programme. At the November council meeting, Gowans and some other members of the council bitterly criticized Akiyoshi Wada, a former Japanese council member, for making public the differences of opinion between Japan and Gowans (see Nature 357, 356; 1992), while other members defended Wada. "It was like a shootout in a Western movie", according to one participant. Cuenod has voiced support for the basic philosophy of the programme as described by Wada.

Although Brenner was also popular with the Japanese, the British delegate did not support Brenner at the November council meeting (Brenner was nominated by Italy). That action effectively killed his candidacy.

David Swinbanks 